\title{
Enhancing Microalgae Cultivation using Biowastes as Growth Media for High Added-Value Co-Products Generation
}

\section{Mohammed Amouri ( $\nabla$ m.amouri@cder.dz)}

Centre de Developpement des Energies Renouvelables https://orcid.org/0000-0002-0542-0341

\section{Fayrouz Kaidi}

Centre de Développement des Énergies Renouvelables: Centre de Developpement des Energies Renouvelables

\section{Amel Ounnar}

Centre de Développement des Énergies Renouvelables: Centre de Developpement des Energies Renouvelables

\section{Majda Aziza}

Centre de Développement des Énergies Renouvelables: Centre de Developpement des Energies Renouvelables

\section{Research Article}

Keywords: Indigenous microalgae, Co-products, Carotenoids, Chlorophylls, Biowastes, pollution abatement, resources recycling

Posted Date: April 20th, 2021

DOI: https://doi.org/10.21203/rs.3.rs-343031/v1

License: (c) (1) This work is licensed under a Creative Commons Attribution 4.0 International License. Read Full License 


\section{Abstract}

This paper aims to study a new growth media using cheese whey and drainage water from agriculture for indigenous microalgae cultivation for value-added product generation. In this context, four combinations are studied beside the BG11 as reference, where BG11/Cheese whey $(60 / 40, \% v / v)$, drainage water $100 \%$, drainage water/Cheese whey $(60 / 40, \% \mathrm{~V} / \mathrm{V})$, and Cheese whey $100 \%$ have been used. Moreover, investigated parameters are biomass dry weight, $\mathrm{pH}$ variation, total chlorophyll and carotenoid content.

Results showed that used growth media have a significant impact on microaglae culture, particularly in terms of cells growth, pigment content and $\mathrm{pH}$ variation. Moreover, the mixture BG11/Cheese whey $(60 / 40, \% v / v)$ shows the best impact for total chlorophylls and carotenoids content. Likewise, the mixture cheese whey/drainage water $(60 / 40, \% \mathrm{~V} / \mathrm{v})$ presents a positive effect on pigments content. The use of cheese whey and drainage water lead to enhance the biomass and pigment production.

This study showed that using agro-industrial C-rich wastes and drainage water enhanced microalgae biomass and pigment content, thus contributing to pollution abatement. This will contribute to both reducing the cost of production and resources recycling.

\section{Introduction}

Microalgae is actually considered as a promising biocatalysts to be implemented in the increasing field of "White Biotechnology" mainly to support the production of food, feed, fine chemicals, and diverse "green energy carriers" (Koller et al. 2014). Algae can biosynthesize an awesome variety of metabolites that could be used as biomaterials with an important potential applications in various industrial sectors (Mehta et al., 2018). According to their high market values, pigments from microalgae have received a particular interest due to its high potential for commercialization despite the need to use new systems for its extraction and purification to reduce its actual high production cost (Ventura et al. 2017). Three major groups of pigments are distinguished in microalgae, namely carotenoids, phycobilins, and chlorophylls; which are applied as nutrient supply, pharmaceutical purposes, as well as in cosmetic industry and food technology (Koller et al. 2014). Furthermore, chlorophyll and carotenoids from microalgae are well established, and its global market has been expanding because of its wide application in human healthcare, food industries, and cosmetics. Likewise, carotenoids are commercially available in several forms including mainly beta-carotene, lutein, lycopene, astaxanthin, zeaxanthin (Mehta et al.,2018; da Silva Ferreira and Sant'Anna 2017). Moreover, the addition of pure carotenoids is a common practice as fish feed for some aquaculture species since it is known to improve carcass and antioxidant capacity (Rosas et al. 2019).

Otherwise, due to its versatile composition, microalgal biomass is presented to be one of the most promising biorefinery feedstock providing alternatives for different areas, such as food, feed, cosmetics and health industries, fertilizers, plastics, and biofuels. Furthermore, microalgae can also be integrated in process of wastewater treatment and $\mathrm{CO}_{2}$ sequestration (Gorry et al. 2018). However, carbon, nutrient, 
and water requirements for microalgae cultivation are still a major bottlenecks for an efficient and costeffective large-scale microalgae biomass production (Kannah et al. 2018). Alternatively, agro-industrial carbon-rich wastes (Biowastes) and wastewaters as source of nutrients are representing an interesting approach to boost algae production with a particular interest for high value added co-products such as pigments, to improve the economics and the sustainability of microalgae biorefinery for an efficient integration with industrial process (Salati et al. 2017); León-Vaz et al. 2019). Moreover, further optimizing culture conditions, by selecting organisms that can overcome the limitations imposed by ambient conditions and that present high pigments content could contribute to lower the cost of microalgae biomass in a biorefinery frame.

This paper aims to study a combination mixture BG11 growth media, cheese whey and wastewater issued from agro-industrial activities, with different proportions. These growth media have been used for indigenous microalga strain mixotrophic cultivation for high added-value co-products production especially chlorophylls and carotenoids. Therefore, cheese whey and drainage water are used as organic carbon and nutriments sources respectively for microalgae cultivation. Furthermore, this study investigates the possibility to integrate microalgae biomass production into an existing industrial sector and wastes recycling to preserve natural resources.

\section{Material And Methods}

The microalgae used in these study was an indigenous strain of Chlorella sp., previously isolated from a local environment and maintained in Erlenmeyer flasks with BG11 medium. Erlenmeyer flasks of $500 \mathrm{~mL}$ were incubated on an orbital shaker under $150 \mathrm{rpm}$ continuous agitation (DaihanScientfic and SHR Digital Shaker, Korea), light intensity of 6000 Lux measured on the external surface of the flasks using a photo flux meter (Model Testo $545 \mathrm{GmbH}$ and CO, Germany). The initial cellular concentration was set approximately to $2 \times 10^{6}$ cells $/ \mathrm{mL}$. The $\mathrm{pH}$ of the culture broth was measured using a digital $\mathrm{pH}$ meter (Starter3100, OHAUS corporation, USA).

Four combinations of growth media are studied beside the BG11 growth media as a reference. BG11/Cheese whey (60/40 \% vv) [BG11/CW], Drainage water 100\% [DW], Drainage water/Cheese whey $(60 / 40 \% \mathrm{vv})$ [DW/CW], and Cheese whey $100 \%$ [CW] are carried out for microalgae characterization aiming the production of high benefit co-products. In order to prevent bacteria contamination, the DW was filtered with $0.45 \mu \mathrm{m}$ vacuum filter holder (Sartorius stedium biotech GMBH-D-37070, Goettingen) and the $\mathrm{CW}$ was autoclaved at $120^{\circ} \mathrm{C}$ for 20 minutes.

The mixotrophic and autotrophic cultures were kept under continuous illumination. The cultures were sampled every two days to monitor growth. Biomass concentration was estimated by measuring the optical density at $680 \mathrm{~nm}$ with UV/Visible spectrophotometer (Lambda 25 UV-visible spectrophotometer, PerkinElmer life and Analytical, UK).Cells were washed 3 times with an equivalent volume of distilled water to avoid excess of sugars and salts (centrifuged for $5 \mathrm{~min}$ at $4000 \mathrm{rpm}$ between each washing). Culture samples were then dried for $24 \mathrm{~h}$ at $70^{\circ} \mathrm{C}$. A good linear regression fit was obtained between the 
dry weight and OD measurements at $680 \mathrm{~nm}\left(\mathrm{R}^{2}\right.$ value of 0.86$)$. The final biomass yield was calculated subtracting the initial biomass used as inoculum and the final biomass at the end of the culture.

The Pigment content determination was carried out according to (Pruvost et al. 2011) using a spectrophotometric method and the following equations are used to determine Chlorophyll $a, b$ and carotenoids.

$[C h l-a] \mu g / m L=-8.0962 \times A_{652}+16.5169 \times A_{665} ; \quad$ Eq. 1

$[\mathrm{Chl}-\mathrm{b}] \mu \mathrm{g} / \mathrm{mL}=27.4405 \times \mathrm{A}_{652}-12.1688 \times \mathrm{A}_{665} ; \quad$ Eq. 2

[Carotenoids] $\mu \mathrm{g} / \mathrm{mL}=4 \times \mathrm{A}_{480}$. $\quad$ Eq. 3

\section{Results And Discussion}

\subsection{Chlorella sp. growth under different growth media}

The cultivation was conducted in the objective to investigate the impact of real growth media on the cell growth and adaptation capacity relatively to conventional BG11 growth media. Chlorella microlagae culture under different growth media shows that chlorella sp. is well adapted to the CW100, CW/DW growth media, where the maximum growth is achieved after the $4^{\text {th }}$ day of culture. On the other hand, all growth media showed a positive effect on the growth of chlorella sp. comparatively to reference BG11 media (Figure1). Moreover, the good growth of chlorella sp. on the CW100 growth media is explained by its high concentration of phosphorus and ammonium (Data are not shown). In this respect, Salati et al., 2017 found that total phosphorus content in the medium was the driving factor affecting algae growth under mixotrophic conditions while carbon availability $\left(\mathrm{BOD}_{5} / \mathrm{COD}\right)$ did not cause any differences in algae kinetic growth parameters and final biomass concentration. However, (Girard et al. 2014) found that the microalgae growth is also affected by the lactose hydrolysis which makes glucose available as carbon source in the growth media since the $3^{\text {rd }}$ day of culture thus increasing biomass production.

It should be noticed that culture growth was undertaken under ambient temperature where its range was from $10^{\circ} \mathrm{C}$ to $18{ }^{\circ} \mathrm{C}$ (winter saison). In this regard, temperature is an important factor affecting microalgal growth and most microalgae prefer an ambient temperature of about $25^{\circ} \mathrm{C}$ to $30^{\circ} \mathrm{C}$ for maximal biomass production without affecting the photosynthetic efficiency (Nagarajan et al. 2019). Likewise, temperature was found to have an impact on the biomass production and microalgae growth. This factor could explain the falling of growth since the $4^{\text {th }}$ day due to temperature decreasing where microalgae cultivation is undertaken at the ambient temperature, where it could be seen the variation of biomass production which is decreased for $\mathrm{CW} 100$ media when the temperature is about $14^{\circ} \mathrm{C}$. In addition, others growth media show a less microalgae growth due to carbon deficiency, whether organic or not. In this context. García-Cubero et al. 2018 have found that the highest biomass productivity and $\mathrm{CO}_{2}$ fixation rates were noticed in the range of $15-25^{\circ} \mathrm{C}$. 


\subsection{Effect of pH growth media on microalgae growth}

The $\mathrm{pH}$ evolution during culture shows a good stability for all growth media. Figure 3 shows a rapid increase in $\mathrm{pH}$ to stabilize near to 11 for both $\mathrm{BG} 11$ and BG11/CW growth media, while for others $\mathrm{pH}$ is stabilized between 9 and 10. Moreover, $\mathrm{pH}$ culture evolution indicates the capacity of this local microalgae to support alkaline conditions. In this regard, Vadlamani et al. 2017 have reported that alkaline conditions permit to improve the $\mathrm{CO}_{2}$ dissolution and to keep an acceptable contamination level avoiding culture failure at large scale.

Chlorella sp. has showed a good adaptation with high value of $\mathrm{pH}$ where it went-up rapidly as showed in figures 1 and 2. In comparable conditions of high pH culture, Vadlamani et al. 2017 have found an equivalent biomass productivity in the range of 1.5 to $2 \mathrm{~g} / \mathrm{L}$ despite low temperature during the culture in the CW100 medium. Likewise, (Qu and Miao 2021) have found that microalgae cultivation under alkaline $\mathrm{pH}$ of 10 conducts to increase biomass yield of $14.1 \%$ comparatively to $\mathrm{pH}$ of 7.5 .

\subsection{Final Biomass production}

Obtained results for biomass production expressed in terms of dry weight $(\mathrm{g} / \mathrm{L})$ showed a good growth with a high final biomass, which could reach five times more the biomass yield of BG11 growth media. According to figure 3, CW100 culture media showed the best final biomass concentration followed by $\mathrm{BG} 11 / \mathrm{CW}$. This result indicates that the CW100 growth media could be used as an alternative for microalgae cultivation and the Chlorella $s p$. algae is showing a good use of organic carbon which presents a good ability for mixotrophic culture.

On the other hand, BG11/CW growth media showed a biomass concentration better than that obtained using DW100 and CW/DW growth media (figure 3). All the combinations growth media used in this study are presenting the highest biomass production comparatively to BG11 growth media. Final biomass yield in mixotrophic cultivation condition using cheese whey as carbon source was obtained by (Girard et al. 2014) to be $3.6 \mathrm{~g} / \mathrm{L}$ after 13 days of culture. In this study, the obtained biomass yield in CW100 growth media is $1.2 \mathrm{~g} / \mathrm{L}$. This value may be due to low temperature during the cultivation period, knowing that temperature is a crucial factor for microalgae growth. In fact, a maximum biomass production is obtained for a temperature between $25^{\circ} \mathrm{C}$ and $30^{\circ} \mathrm{C}$ without affecting the photosynthetic efficiency (Nagarajan et al. 2019).

\subsection{Pigments content determination}

\subsubsection{Total Chlorophylls}

Chlorophyll is one of the valuable bioactive compounds that can be extracted from microalgal biomass. It is used as a natural food coloring agent and has antioxidant as well as antimutagenic properties (Hosikian et al. 2010). As showed in figure 4, chlorophylls content under mixtrophic culture is more important where it could reach $50 \mathrm{mg} / \mathrm{g}$ dry weight for both CW/DW and BG11/CW. Furthermore, DW100, 
CW100, and BG11 growth media showed also a good total chlorophylls content, with values in the range of $10 \mathrm{mg} / \mathrm{g}$ to $30 \mathrm{mg} / \mathrm{g}$ dry weight. Based on these results, using carbon rich biowastes combined to a source of mineral nutrients would improve chlorophylls content.

As reported in literature, total chlorophylls content for Chlorella $s p$. is found in the range of 22.6 to 32.4 $\mathrm{mg} / \mathrm{g}$ dry weight (Figueroa-Torres, Gonzalo M. et al. 2020). Moreover, the most abundant pigment in Chlorella vulgaris is chlorophyll, which can reach $1-2 \%$ dry weight, also the content of total chlorophylls varies from 0.3-15.4 mg/g dry weight (Safi et al. 2014).

The high content in total chlorophylls is due to the supplementation of glucose derived from cheese whey degradation as a carbon source at low concentration $(4 \mathrm{~g} / \mathrm{L})$ which promotes the biosynthesis of chlorophylls. In addition, it has been found that all glucose could be exhausted within 7 days, which explains the maximum content observed during the $8^{\text {th }}$ day of culture and the decreasing of the chlorophylls after this period maintaining its content almost the same with others growth media (Chai et al. 2018).

Many Strategies have been reported in order to promote the chlorophyll content in microalgae including variation in light intensity, culture agitation, changes in temperature and nutrient availability. Nitrogen and phosphorus are essential nutrients for microalgae culture and then critical for the synthesis of chlorophyll molecules. A deficiency in these two elements can induce respectively $64 \%$ and $67 \%$ reduction in chlorophyll content (da Silva Ferreira and Sant'Anna 2017).

\subsubsection{Total Carotenoids}

Fig. 5 shows the evolution of total carotenoids content under different growth media. Carotenoids content evolution showed practically a good tendency for all growth media until the 10th day, which could reach more than $1 \%$ of dry weight even if temperature is very low. However, it was found that growth media composed of BG11/CW presents the best content after the 10th day which are in the same range of those reported in literature where quantity of carotenoids (lutein) extracted from Chlorella sp. in mixtrophic cultivation was found to be about $6.83 \mathrm{mg} / \mathrm{g}$ dry weight (Gong and Huang 2020). Furthermore, total carotenoids of $2.7-8.3 \mathrm{mg} / \mathrm{g}$ dry weight for chlorella genus were reported in literature (Figueroa-Torres, Gonzalo M. et al. 2020).

The high content of carotenoids in BG11/CW and BG11 growth media is probably due to their nitrogen availability, where nitrogen is a major essential element for both cell growth and lutein accumulation. This latter is a primary carotenoid under no stress conditions, where a content of $8.39 \mathrm{mg} / \mathrm{g}$ of lutein is reported for Chlorella sorokenia (Xie et al. 2019). Moreover, it has been reported that increasing in glucose concentration increase lutein content (Minhas et al. 2016). Likewise, glucose derived from cheese whey degradation stimulates the microalgae to produce carotenoids (Chen et al. 2018; Gong and Huang 2020).

\section{Conclusion}


Microalgae are considered as excellent candidates for bioactive compounds, yet microalgal residues remaining after the extraction of one or two compounds are usually discarded, which is not economical. The aim of this work was to evaluate new growth media combination issued from waste sources, used for microalgae cultivation for biomass and pigments production the objective to decrease the cost of production and wastes recycling, thus preserving natural resources.

Results showed that new growth media used for microalgae cultivation have a significant impact on microaglae culture, particularly in terms of growth, $\mathrm{pH}$ evolution, chlorophylls and carotenoids concentration. Moreover, the mixture of BG11/Cheese whey $(60 / 40 \% v v)$ shows the best performance for both total chlorophylls and carotenoid content. Likewise, $\mathrm{pH}$ evolution presents a good stability, which is an important factor for microalgae cultivation. In addition, using the Cheese whey could be a good growth media to support microalgae cultivation for biomass production. The mixture cheese whey/drainage water $(60 / 40 \% v v)$ present a significant impact on the pigment content of microalgae biomass. Finally, the use of cheese whey and drainage water lead to enhance the biomass and pigment production.

Using agro-industrial carbon-rich biowastes and wastewater as growth media for chlorophyll and carotenoid production under alkaline conditions represents a promising approach to boost microalgae integration in existing industries in a more sustainable way. Moreover, the use of high-performance strains with a high added-value products potential alongside the use of waste carbon and nutriment rich combination for mixotrophy microalgae cultivation would offer the most economic, environmentalfriendly and sustainable algae-refinery. Nevertheless, further optimizing culture conditions by selecting strains is still needed to overcome the limitations imposed by ambient conditions.

\section{Declarations}

Funding: This study was funded by Direction Générale de la Recherche Scientifique et Développement Technologique of Algeria.

Acknowledgements: Authors greatly acknowledge the Direction Générale de la Recherche Scientifique et Développement Technologique of Algeria for its financial support.

Authors contributions M AMOURI: conceptualization, original manuscript writing, editing; M AMOURI, F KAIDI: investigation, resources, data collection; M AZIZA, A OUNNAR: review and editing.

Ethics approval and consent to participate (Not applicable)

\section{Consent for publication (Not applicable)}

Availability of data and materials: All data generated or analyzed during this study are included in this published article

Competing interests: The authors declare that they have no competing interests 


\section{References}

1. Chai S, Shi J, Huang T et al (2018) Characterization of Chlorella sorokiniana growth properties in monosaccharide-supplemented batch culture. PLoS ONE 13:e0199873. https://doi.org/10.1371/journal.pone.0199873

2. Chen C-Y, Lu I-C, Nagarajan D et al (2018) A highly efficient two-stage cultivation strategy for lutein production using heterotrophic culture of Chlorella sorokiniana MB-1-M12. Biores Technol 253:141147. https://doi.org/10.1016/j.biortech.2018.01.027

3. da Silva Ferreira V, Sant'Anna C (2017) Impact of culture conditions on the chlorophyll content of microalgae for biotechnological applications. World J Microbiol Biotechnol 33:20. https://doi.org/10.1007/s11274-016-2181-6

4. Figueroa-Torres GM, Padilla B, Pittman E, Constantinos JK T (2020) Microalgae strain catalogue (2nd Edition). Zenodo. DOI: 10.5281/ZENODO.3780067

5. García-Cubero R, Moreno-Fernández J, Acién-Fernández FG, García-González M (2018) How to combine $\mathrm{CO} 2$ abatement and starch production in Chlorella vulgaris. Algal Res 32:270-279. https://doi.org/10.1016/j.algal.2018.04.006

6. Girard J-M, Roy M-L, Hafsa MB et al (2014) Mixotrophic cultivation of green microalgae Scenedesmus obliquus on cheese whey permeate for biodiesel production. Algal Res 5:241-248. https://doi.org/10.1016/j.algal.2014.03.002

7. Gong Y, Huang J (2020) Characterization of four untapped microalgae for the production of lipids and carotenoids. Algal Res 49:101897. https://doi.org/10.1016/j.algal.2020.101897

8. Gorry PL, Sánchez L, Morales M (2018) Microalgae Biorefineries for Energy and Coproduct Production. Green Energy and Technology undefined-undefined. https://doi.org/10.1007/978-3-31969093-3_5

9. Hosikian A, Lim S, Halim R, Danquah MK (2010) Chlorophyll Extraction from Microalgae: A Review on the Process Engineering Aspects. International Journal of Chemical Engineering 2010:1-11. https://doi.org/10.1155/2010/391632

10. Kannah RY, Velu C, Rajesh Banu J et al (2018) Food Waste Valorization by Microalgae. In: Singhania RR, Agarwal RA, Kumar RP, Sukumaran RK (eds) Waste to Wealth. Springer Singapore, Singapore, pp 319-342

11. Koller M, Muhr A, Braunegg G (2014) Microalgae as versatile cellular factories for valued products. Algal Res 6:52-63. https://doi.org/10.1016/j.algal.2014.09.002

12. León-Vaz A, León R, Díaz-Santos E et al (2019) Using agro-industrial wastes for mixotrophic growth and lipids production by the green microalga Chlorella sorokiniana. New Biotechnol 51:31-38. https://doi.org/10.1016/j.nbt.2019.02.001

13. Mehta P, Singh D, Saxena R et al (2018) High-Value Coproducts from Algae-An Innovational Way to Deal with Advance Algal Industry. In: Singhania RR, Agarwal RA, Kumar RP, Sukumaran RK (eds) Waste to Wealth. Springer Singapore, Singapore, pp 343-363 
14. Minhas AK, Hodgson P, Barrow CJ, Adholeya A (2016) A Review on the Assessment of Stress Conditions for Simultaneous Production of Microalgal Lipids and Carotenoids. Front Microbiol 7:. https://doi.org/10.3389/fmicb.2016.00546

15. Nagarajan D, Lee D-J, Chang J-S (2019) Integration of anaerobic digestion and microalgal cultivation for digestate bioremediation and biogas upgrading. Biores Technol 290:121804. https://doi.org/10.1016/j.biortech.2019.121804

16. Pruvost J, Van Vooren G, Le Gouic B et al (2011) Systematic investigation of biomass and lipid productivity by microalgae in photobioreactors for biodiesel application. Biores Technol 102:150158. https://doi.org/10.1016/j.biortech.2010.06.153

17. Qu D, Miao X (2021) Carbon flow conversion induces alkali resistance and lipid accumulation under alkaline conditions based on transcriptome analysis in Chlorella sp. BLD Chemosphere 265:129046. https://doi.org/10.1016/j.chemosphere.2020.129046

18. Richmond A, Hu Q (eds) (2013) Handbook of Microalgal Culture: Applied Phycology and Biotechnology. John Wiley \& Sons, Ltd, Oxford

19. Rosas VT, Monserrat JM, Bessonart M et al (2019) Comparison of $\beta$-carotene and Spirulina (Arthrospira platensis) in mullet (Mugil liza) diets and effects on antioxidant performance and fillet colouration. J Appl Phycol 31:2391-2399. https://doi.org/10.1007/s10811-019-01773-1

20. Safi C, Zebib B, Merah 0 et al (2014) Morphology, composition, production, processing and applications of Chlorella vulgaris: A review. Renew Sustain Energy Rev 35:265-278. https://doi.org/10.1016/j.rser.2014.04.007

21. Salati S, D'Imporzano G, Menin B et al (2017) Mixotrophic cultivation of Chlorella for local protein production using agro-food by-products. Biores Technol 230:82-89. https://doi.org/10.1016/j.biortech.2017.01.030

22. Vadlamani A, Viamajala S, Pendyala B, Varanasi S (2017) Cultivation of Microalgae at Extreme Alkaline pH Conditions: A Novel Approach for Biofuel Production. ACS Sustainable Chem Eng 5:7284-7294. https://doi.org/10.1021/acssuschemeng.7b01534

23. Ventura SPM, Nobre BP, Ertekin F et al (2017) 19 - Extraction of value-added compounds from microalgae. In: Gonzalez-Fernandez C, Muñoz R (eds) Microalgae-Based Biofuels and Bioproducts. Woodhead Publishing, pp 461-483

24. Xie Y, Li J, Ma R et al (2019) Bioprocess operation strategies with mixotrophy/photoinduction to enhance lutein production of microalga Chlorella sorokiniana FZU60. Biores Technol 290:121798. https://doi.org/10.1016/j.biortech.2019.121798

\section{Figures}




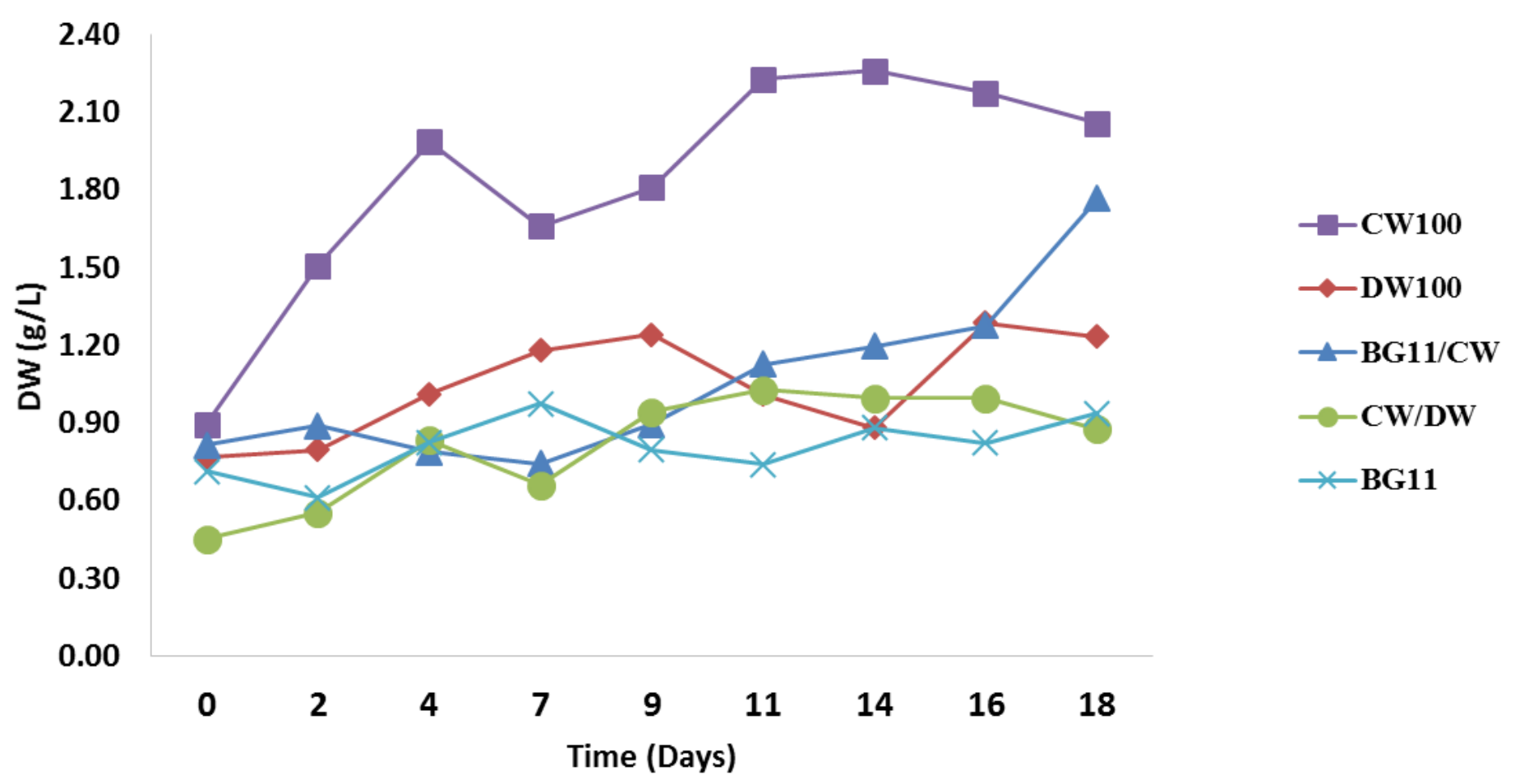

Figure 1

Dry weight evolution under different growth media combination

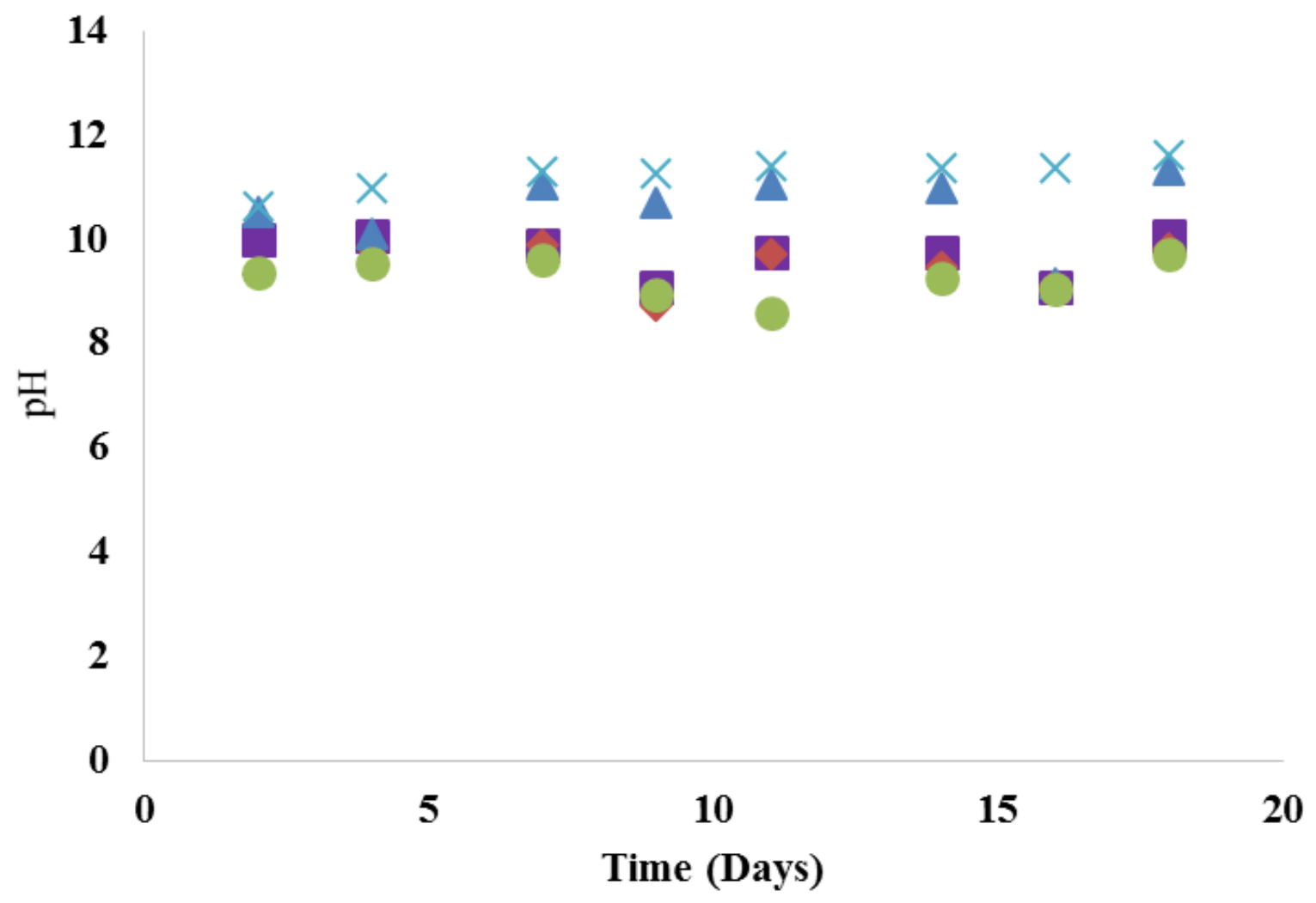

Figure 2 


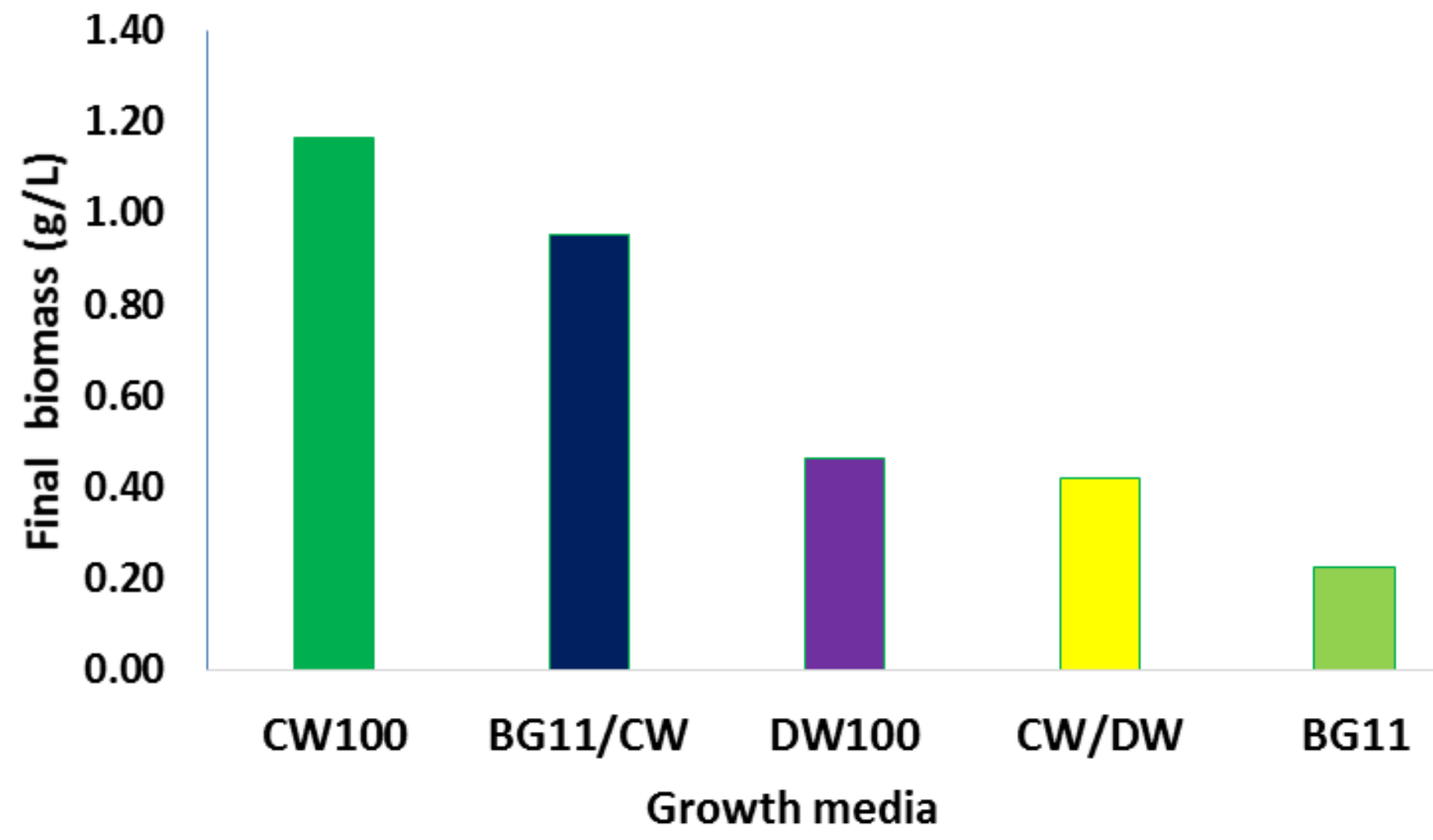

Figure 3

Biomass yield for different growth media 


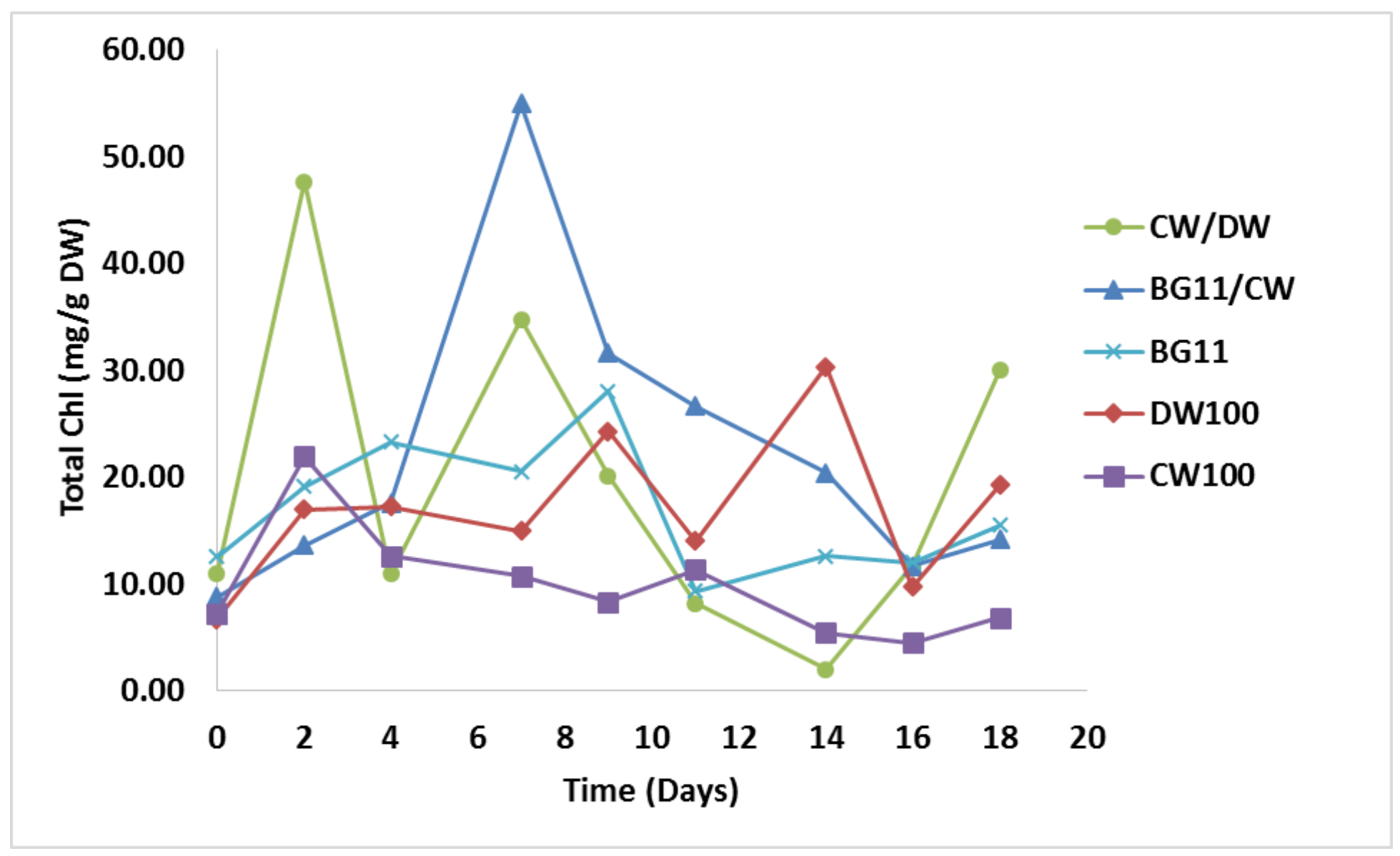

Figure 4

Chlorophylls content under different growth media combination 


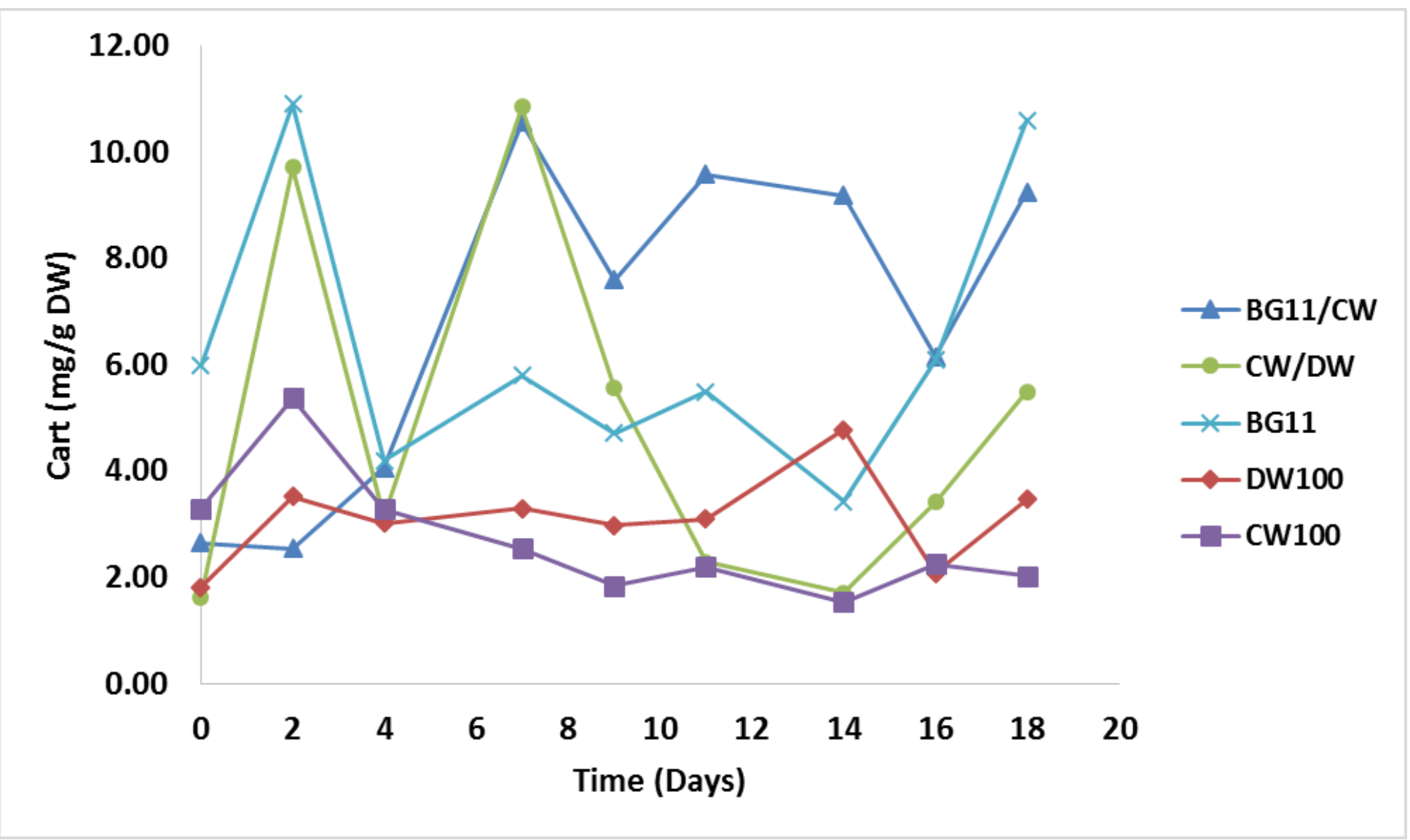

Figure 5

Carotenoids content under mixotrophic culture using different growth media 